\title{
Las dimensiones olvidadas de los programas de VIH dirigidos a las waria de Jogjakarta, Indonesia
}

\author{
NÉSTOR NUÑO MARTÍNEZ
}

A pesar de los esfuerzos realizados por la Comisión Nacional Indonesia para el Sida - Komisi Penanggulanga AIDS -, desde la década de 1990, los programas de prevención y tratamiento del VIH no han logrado controlar el avance de la enfermedad en el país. Este artículo analiza la implementación de los programas llevados a cabo con las waria - travestis femeninos en Indonesia-. Si bien las organizaciones atribuyen la aparición de nuevas infecciones y abandonos de la terapia antirretroviral a la falta de educación y responsabilidad individual entre las waria, el análisis pormenorizado de estas iniciativas revela la existencia de factores estructurales, socioeconómicos y relacionales que inciden en la transmisión del virus y que son pobremente considerados por las entidades promotoras.

PALABRAS CLAVE: VIH/Sida, Indonesia, desarrollo, waria, enfoques estructurales

The Forgotten Dimensions of HIv Programs Conducted with Waria in Jogjakarta, Indonesia

Despite the great efforts conducted by the Indonesian National AIDS Commission -Komisi Penanggulanga AIDS - since the 1990s, the programs to prevent and treat HIV have failed to effectively control the spread of the disease in the country. This article focuses on HIV programs targeting waria - male-to-female transvestites in Indonesia-. Organizations blame the lack of education and of individual responsibility among waria for the appearance of new diseases and the abandon of the medical treatment. However, analysis reveals that the success of these programs is influenced by strong structural, socioeconomic and relational constrains that are seldom conside-

NÉSTOR NUÑO MARTÍNEZ red by implementing organizations.

orcid.org/0000-0002-4958-6394

Department of Epidemiology and Public Health, Schweizerisches TropenKEYWORDS: HIV/AIDS, Indonesia, development, waria, structural approaches

und Public Health-Institut,

Basilea, Suiza

nenunom@gmail.com 


\section{Introducción ${ }^{1}$}

$\mathrm{D}$

esde que el primer caso de infección por el virus de la inmunodeficiencia humana (VIH) fue detectado en la isla de Bali a finales de la década de 1980, el Sida se ha convertido en un problema relevante de salud pública en Indonesia. El número de personas portadoras del virus ha crecido de manera desbocada, pasó de 7195 en 2006 a 76879 en 2011, y ha colocado al VIH en la patología transmisible con mayores índices de crecimiento del país (Gunawan, Kosen y Simms, 2006; Indonesian National AIDS Commission, 2012; ONUSIDA, 2013).

Estas inquietudes se han canalizado en innumerables estrategias de prevención y tratamiento promovidas por el Estado indonesio, organismos internacionales y donantes privados que en los últimos años han intentado controlar y estabilizar la expansión de la epidemia. La lógica de estos programas se ha caracterizado por una fuerte influencia de las construcciones hegemónicas de la enfermedad (O'Manique, 2004; Ramin, 2007), que recurren a datos estadísticos y modelos epidemiológicos con la finalidad de seleccionar grupos poblacionales en los cuales focalizar los programas, con la finalidad de reducir el impacto en el conjunto de la población.

La mayoría de las estrategias implementadas en Indonesia para dar respuesta a la epidemia del VIH está centrada en grupos minoritarios —e. g., trabajadoras sexuales y usuarios de drogas inyectables- y no se contemplan otros grupos sociales que interactúan con ellos, como los clientes sexuales (Hammar, 2010). En respuesta al crecimiento alarmante de los casos de transmisión del VIH entre la población en general (ONUSIDA, 2012), el gobierno indonesio comenzó a expandir sus programas de prevención a otros grupos poblacionales. La campaña Bangga Aku Aku Tahu —Estoy Orgulloso de Conocerlo- se enfoca en educar a adolescentes de 15 a 24 años de edad sobre la importancia de prevenir el sexo premarital y los 
peligros de la enfermedad. La elección de este grupo de edad pone en evidencia las lógicas epidemiológicas que guían los programas en el país. Para su elección se ha considerado el periodo de incubación de la enfermedad — entre cinco y diez años- y los últimos indicadores estadísticos, que muestran una prevalencia significativa de la enfermedad entre la población de 20 a 25 de años de edad (Bappenas, 2012: 72).

En Indonesia, durante siglos, se han transgredido las dicotomías del género masculino/femenino (Boellstorff, 2005; Peletz, 2006; 2011). El término waria es el neologismo actual ${ }^{2}$ utilizado para describir a los travestis femeninos ${ }^{3}$ del país. Las waria son sujetos de cuerpo masculino que no siguen los estereotipos sociales asociados a la masculinidad, pues usan ropa femenina (Oetomo, 2002) y se describen como "almas femeninas atrapadas en cuerpos masculinos" (Boellstorff, 2004).

Con frecuencia, las waria han sido consideradas "población en riesgo" del viH debido a los altos índices de transmisión y prevalencia del virus en este grupo (Joesoef et al., 2003; Morin, 2008; Nicholas, Siregard y Ngatimin, 1997; Pisani et al., 2004; Prabawanti et al., 2011; Indonesian National AIDS Commission, 2012: 33). Hasta la fecha, no se han realizado investigaciones que profundicen en los problemas del VIH entre las waria, más allá de las clasificaciones epidemiológicas y las cifras estadísticas. Este artículo propone un análisis del impacto sociocultural y estructural de la enfermedad entre las waria de la ciudad de Jogjakarta, Indonesia. Primero se describen los programas de prevención y tratamiento del VIH que varias organizaciones no gubernamentales $(\mathrm{ONG})^{4} \mathrm{y}$ de base han realizado con las waria de Jogjakarta desde hace décadas. Este análisis permite determinar los logros y debilidades de los programas, y revela la existencia de factores socioculturales y estructurales que inciden en la transmisión del virus y que han sido invisibilizados de manera sistemática. La presencia de estas dimensiones olvidadas es relevante para discutir la importancia del uso de perspectivas que traten el estudio de la epidemia del VIH desde enfoques multidisciplinarios.

\section{Metodología}

La información utilizada en este artículo procede de una investigación llevada a cabo entre febrero y mayo de 2014 en la ciudad de Jogjakarta, Indonesia, ${ }^{5}$ en la que se realizó un total de 35 entrevistas semiestructuradas a miembros de ONG, organizaciones de base, waria, médicos, personal sanitario, líderes religiosos locales y ustadz — predicadores de la fe islámica- Las entrevistas se hicieron en inglés y bahasa —indonesio-, según la conveniencia del informante. Fueron transcritas verbatim con el software Express Scribe y analizadas de manera sistemática por medio de categorías analíticas. También se realizaron observaciones participantes en áreas

2

Dédé Oetomo (2000: 57-58) y Tom Boellstoff (2004: 162) explican que el término fue acuñado a finales de la década de 1970 por la conjunción de las palabras indonesias wanita, mujer, y pria, hombre. En este artículo utilizaré el término waria tanto para la forma singular como para la plural, como se usa en el idioma indonesio, en el que no existe la diferenciación entre ambas formas.

3 En los estudios de género, las waria son categorizadas como transgénero. Sin embargo, rehúso utilizar ese término por sus implicaciones políticas, que han dado lugar a que la noción de transgénero se conciba como una categoría ambigua y de marcados matices etnocéntricos (Valentine, 2007).

$4 \quad$ También llamadas organizaciones de la sociedad civil.

5 Esta investigación formó parte del proyecto "Happiness in Times of HIV: An Ethnographic Exploration of Waria Experiences" - La felicidad en tiempos del VIH: una etnografía exploratoria de las experiencias waria-, dirigido por Sylvia Tidey, y fue financiada parcialmente por el Graduate School of Social Sciences Fieldwork Subsidy y el Graduate School of Social Sciences Local Supervisor Fee de la Universidad de Ámsterdam. 
populares entre trabajadoras sexuales waria, vecindarios de residencia de grupos waria, actos públicos y religiosos, y dos hospitales donde había waria hospitalizadas. Por último, se moderaron dos grupos de discusión con diez y siete waria, respectivamente. Su análisis fue similar al de las entrevistas. Los nombres reales de los participantes han sido sustituidos por seudónimos con la finalidad de mantener su confidencialidad e integridad.

\section{El impacto y las respuestas ante la epidemia del $\mathrm{VIH}$ entre las waria de Jogjakarta}

Situada en el centro de la isla de Java y con una población cercana a los 600000 habitantes (BPS, 2010), la ciudad de Jogjakarta es un vibrante nodo comercial, histórico, turístico y académico en Indonesia. La ciudad se conoce también porque alberga una importante población de waria, que oscila entre 80 y 300 miembros. ${ }^{6}$

Desde hace décadas, el viH ha tenido un impacto especial entre las waria de Jogjakarta. Aunque no existen estadísticas oficiales, de acuerdo con la ONG Perkumpulan Keluarga Berencana Indonesia (PKBI) - Asociación Indonesia de Planificación Familiar-, alrededor de 30\% de las waria de la ciudad están infectadas con el VIH. Desde la década de 1980, la PKBI ha desarrollado programas con las waria de Jogjakarta para prevenir la transmisión del virus. Al comienzo, la PKBI centró sus esfuerzos en la provisión de información sobre infecciones de transmisión sexual (ITS) y la promoción de programas de desarrollo económico. Este escenario cambió de manera drástica en 1993, cuando el primer caso de infección por VIH se detectó entre las waria de la ciudad. Entonces, la Asociación pasó a concentrar sus esfuerzos en la prevención de la transmisión. Actualmente, la PKBI promueve cuatro programas principales: charlas mensuales sobre la prevención del viH; educadores de pares ${ }^{7}$ que promueven el uso de condones, en especial ente entre las waria trabajadoras sexuales; programas gratuitos de asesoría y pruebas voluntarias del VIH (APV), ${ }^{8}$ y una clínica móvil que se desplaza a las zonas de residencia de waria para realizar el APV.

Por otro lado, Keluar Besar Waria Yogyakarta (Kebaya) — Gran Familia Waria Jogjakarta — es una organización de base fundada en 2004 por un grupo de waria con experiencia en educación de pares en la PKBI. Debido al importante incremento de los casos de infecciones por VIH entre las waria y la negativa de la PKBI a proveer terapia antirretroviral (TAR), estas waria se movilizaron para ofrecer asistencia médica a las waria seropositivas.

Al comienzo, Kebaya no tenía recursos económicos para proveer TAR y se vio forzada a negociar la distribución de los medicamentos con facultativos médicos. En 2006, empezó a recibir financiamiento de organismos y fundaciones internacionales, como el Programa Conjunto de las Naciones Unidas sobre el VIH/Sida (ONUSIDA) (2006-2007), ${ }^{9}$ Hivos (2007-2008) y The Global

$6 \quad$ Existen varias estimaciones sobre el número de waria que vive en la ciudad. De acuerdo con la Perkumpulan Keluarga Berencana Indonesia (PKBI), hay alrededor de 100 waria. Esta cifra difiere de manera significativa de las de otras organizaciones. La ong Komunitas AIDS Indonesia calcula entre 80 y 130 waria, y los líderes de Ikatan Waria Jogjakarta - Comunidad Waria Jogjakarta- estiman casi 300. Es complicado constatar la certeza de estos datos, pues no existe un censo oficial y la movilidad de waria procedentes de otras regiones del país hacia Jogjakarta es constante.

7 Estos educadores promueven el intercambio de información, valores y ejemplos con la finalidad de producir cambios en las actitudes y prácticas saludables de sus pares (OMS, 2014). Este enfoque ha sido largamente discutido en la medida en que plantea importantes prenociones y perspectivas etnocéntricas respecto a los procesos participativos y educativos (Pérez, 2012).

8 Protocolo que combina la prueba clínica del VIH con el asesoramiento sobre la enfermedad y su tratamiento, para cambiar actitudes y nociones respecto a la enfermedad y su transmisión.

9 Que comenzó a ser operativo en 1996. 
Fund (2009-2010). ${ }^{10}$ Aunque en la actualidad Kebaya no recibe financiamiento externo, sigue proveyendo TAR gratuitamente a las waria, gracias a un acuerdo entre el gobierno indonesio y The Global Fund. Al mismo tiempo, Kebaya ha complementado el aprovisionamiento de TAR con otros dos programas: la creación de un grupo de apoyo llamado Violet, en el que las waria seropositivas pueden compartir sus experiencias, miedos e incertidumbres, y el desarrollo de un protocolo de monitoreo de la TAR. Las nuevas waria seropositivas deben convivir durante un tiempo variable en la sede de Kebaya hasta que sus integrantes acrediten que están adscritas al tratamiento. Una vez que dejan la sede, reciben asesoría de voluntarios que las ayudan a solucionar problemas derivados de la terapia. ${ }^{11}$

\section{Las ambivalencias al descubierto. Luces y sombras de los programas de prevención y tratamiento del VIH}

Con el paso de los años, la implementación de los programas de la PKBI y Kebaya ha dado lugar a resultados significativos. Uno de los logros más relevantes es la aceptación del uso del condón entre las trabajadoras sexuales waria. Las waria relatan que antes de la llegada del programa los clientes preferían a aquellas predispuestas a tener sexo sin protección. Esto provocaba que numerosas waria que conocían la importancia de practicar sexo seguro terminaran cediendo ante los clientes por miedo a perder su modo de subsistencia. En 2006, las waria de las zonas de trabajo sexual BI y Tugu Station acordaron el uso obligatorio de condones. Las waria que se negaron fueron forzadas a desplazarse a otros espacios más apartados de la ciudad, como Prambanan, donde el uso de condones sigue siendo una cuestión de negociación entre las waria y los clientes.

Otrologro destacado esla promociónymantenimiento de los mecanismos para el aprovisionamiento

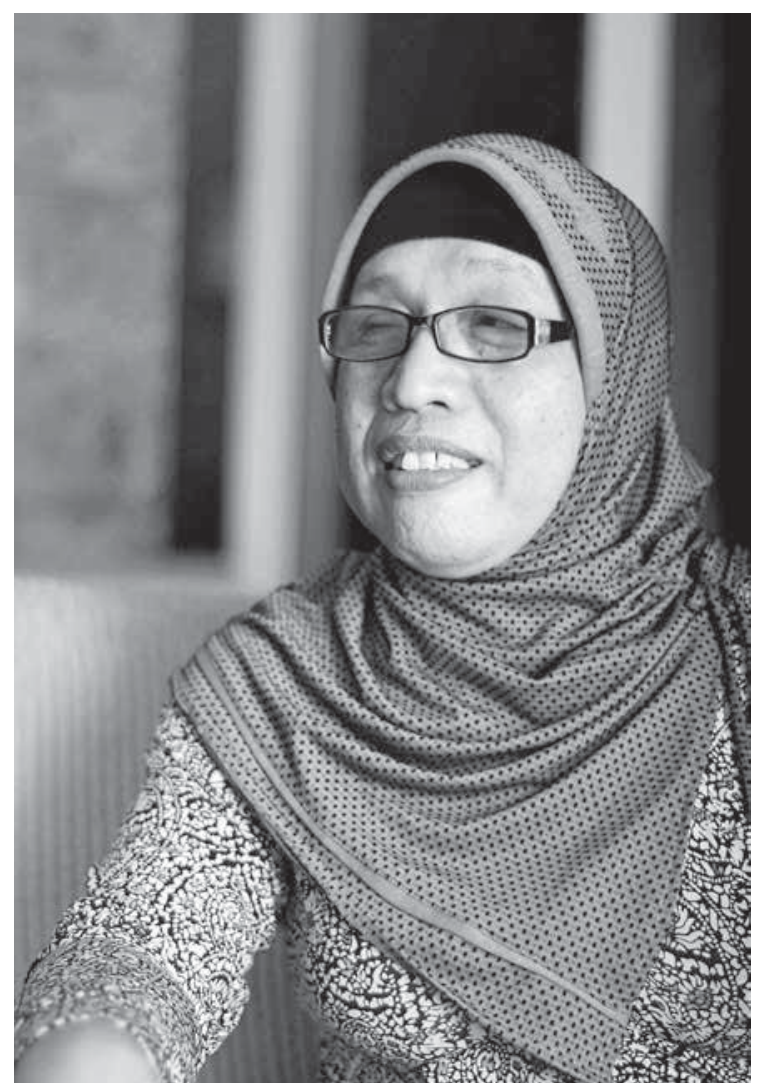

NÉStor Nuño MARTínez • Miembro de Keluar Besar Waria Yogyakarta (Kebaya) - Gran Familia Waria Jogjakarta-. Jogjakarta, Indonesia, 2014

de APV y TAR gratuitas. Desde 2008, las waria de la ciudad pueden hacer uso del APV de forma rápida y sencilla en la clínica que la PKBI tiene en el barrio Badram, en diversos puskesmas — centros de atención

Hivos es una organización holandesa dedicada al desarrollo internacional, fundada en 1968. Sus programas se centran en la provisión de soporte económico a organizaciones en África, Latinoamérica y Asia. Sus principales áreas de intervención son el cambio social, el activismo digital y las innovaciones rurales. The Global Fund es una organización financiera dedicada al financiamiento de programas de prevención de patología, como el VIH, la tuberculosis o la malaria. Fue fundada en 2002 y su mayor inversor privado es la Fundación Gates.

11 A la fecha, Kebaya asiste a 50 personas, 35 son waria, y el resto, hombres homosexuales. 
primaria- que mantienen convenios con la PKBI y Kebaya, en el hospital público Sardijto y en la clínica móvil de la PKBI. Para obtener la TAR, las waria deben ponerse en contacto con Kebaya, que gestiona los trámites con el gobierno en aproximadamente dos semanas, y después recoger su medicación mensual en el hospital Sardjito. Aunque no hay estadísticas oficiales al respecto, las waria consideran que el impacto de estos programas ha sido significativo. En 2005, al menos siete waria murieron en un mes, y entre 2010 y 2012, diez waria perecieron. Desde 2013, no ha habido noticias sobre waria fallecidas a causa del Sida.

Sin duda, estos programas han mejorado de forma sustancial la calidad de vida de las waria. Sin embargo, este éxito debe contextualizarse a la luz de lagunas o "cuellos de botella" que han surgido durante su implementación. A pesar de la regulación sobre el uso obligatorio de condones en BI y Tugu Station, sigue habiendo casos de transmisión del VIH entre las waria que trabajan en estas áreas. Las waria destacan la importancia de usar condones, pero los clientes todavía se muestran reacios a utilizarlos por dos motivos principales: i) consideran que si las waria les piden que los usen es porque sospechan que tienen alguna ITS, y ii) perciben que el uso de condones durante el coito implica un menor grado de placer (Thomsen, Stalker y Toroitich-Ruto, 2004). Por consiguiente, los clientes habituales intentan negociar el uso de condones al esgrimir su responsabilidad, prudencia y frecuencia como recursos legitimadores. Algunas waria ceden a los deseos de estos clientes ante la aprensión de perder una fuente de ingresos que consideran regular. Algunas de estas waria también perciben que las prácticas sexuales sin condón con clientes habituales son seguras porque consideran que éstos no tienen otras compañeras sexuales. Por lo regular, esta creencia se encuentra alejada de la realidad, como muestran otras investigaciones al respecto en lugares como Uganda, donde un gran número de clientes sexuales regulares también mantiene relaciones con otras trabajadoras sexuales y cónyuges, lo que magnifica el riesgo de transmisión del VIH (Gysels, Pool y Bwanika, 2001).

De manera simultánea, los logros de los programas de APV y TAR deben ser discutidos. A pesar de su gratuidad y accesibilidad, todavía hay waria que rehúsan utilizarlos: "tenía una amiga en Solo [zona de la ciudad donde residen waria]. Cuando vimos su estado físico, parecía que tenía Sida. Todas intentamos decirle que se hiciera las pruebas, pero siempre se negaba [...], no podíamos forzarla, ¿no?” (Nancy, 12 de marzo de 2014).

Estos problemas también se reflejan en varios casos de waria seropositivas que deciden dejar la TAR e incluso escapan de los hospitales u ocultan su medicación bajo el colchón para engañar a las enfermeras: "ella tenía alucinaciones. Dejó de tomar la medicación y le dijo a sus amigas que si tomaban la medicación les pasaría lo mismo. Ella estaba muy asustada [...], todavía estamos esperando a ver si cambia de parecer" (Kira, 6 de abril de 2014).

Tanto la PKBI como Kebaya atribuyen estas complicaciones a la falta de responsabilidad y conocimiento por parte de las waria. En su opinión, el miedo a los efectos secundarios ${ }^{12}$ es una de las principales explicaciones a la falta de adscripción a los programas. Las organizaciones también consideran que algunas waria deciden dejar la TAR una vez que perciben que su estado de salud ha mejorado o porque les incomoda tener que seguir horarios estrictos de medicación, así como dietas que excluyen el consumo de alcohol y otras drogas. Las soluciones promovidas por la PKBI y Kebaya para tratar estos "cuellos de botella" se centran en el control y cuidado individual y la promoción de actividades

\footnotetext{
12 Los efectos varían en cada caso. Los más comunes indicados por las waria son mareos, pérdida de conciencia, náuseas, picores y erupciones cutáneas, alucinaciones o fuertes dolores de cabeza.
} 
que subrayan los beneficios que estos programas tienen para la salud, por ejemplo, charlas educativas, grupos de apoyo o estrategias para monitorear la adscripción a la TAR. Todas estas estrategias siguen principios y lógicas planteados por paradigmas de carácter individualista aplicados al campo de la salud, como el Modelo Económico del Comportamiento (Datta y Mullainathan, 2012; Frey y Serna, 1992). Sin embargo, para comprender la naturaleza de estos obstáculos es necesario mirar más allá del componente individual y considerar otras dimensiones, como el estigma hacia las waria seropositivas, la discriminación socioeconómica o la falta de confianza hacia las instituciones que coordinan los programas.

\section{Discriminación, estigma y rumores. Las dimensiones olvidadas del VIH}

En palabras de O'Manique (2004), las respuestas al VIH no pueden entenderse como ejercicios de cientificismo racional objetivo libre de interpretaciones, sino que están atravesadas por dimensiones políticas, sociohistóricas y económicas. A lo largo de la historia, dos modelos dominantes han construido la enfermedad a través de determinadas lentes hegemónicas. Estos modelos influyen de manera significativa en la forma en la que se construye el VIH, y se concibe su prevención y tratamiento (Jain, s. f.). Por un lado, el paradigma biomédico o de la medicina clínica esboza que el Sida es una patología

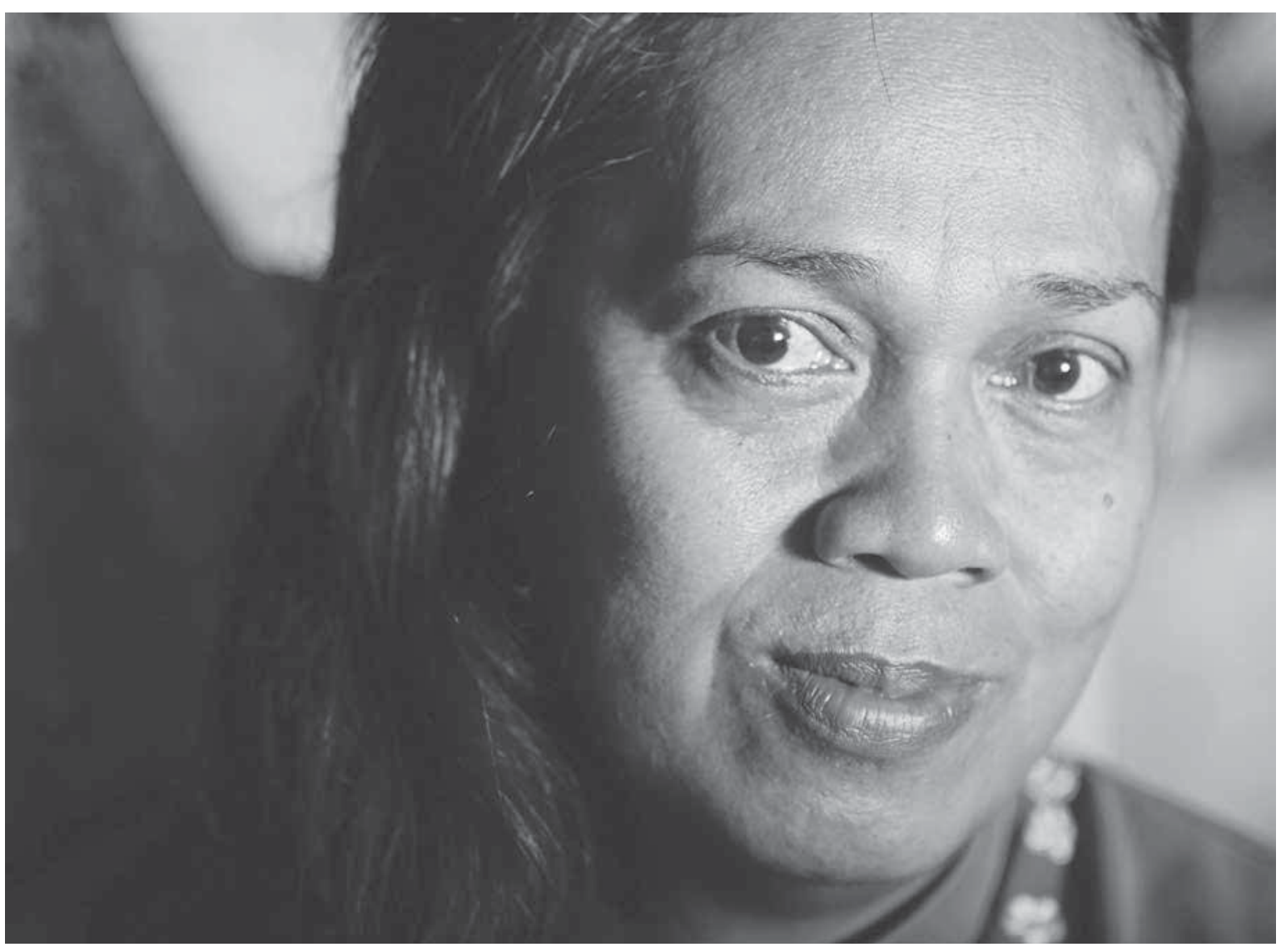

NÉStor Nuño MARTíneZ • Waria. Jogjakarta, Indonesia, 2014. 
que resulta de una infección vírica. En este sentido, la enfermedad se concibe sólo dentro de los límites biológicos y se restringe al plano corporal (Menéndez, 1988), lo que a priori permite su "universalización objetiva”. Según este modelo, la única estrategia para acercarse a la prevención y tratamiento del VIH es la aplicación del conocimiento y las tecnologías biomédicas. Por otro lado, el paradigma de la salud pública plantea una construcción alternativa. Para este modelo, la transmisión del VIH es consecuencia de comportamientos de riesgo, por ejemplo, prácticas sexuales sin condón o el uso de agujas no esterilizadas para la inyección de drogas intravenosas. Este paradigma considera que la reducción de la transmisión se consigue por medio de la modificación de hábitos inapropiados. De ahí que este modelo haga hincapié en la importancia de las estrategias de prevención y no en el tratamiento.

Estos dos modelos se han utilizado de manera complementaria durante décadas en los programas de salud internacional, como reflejan las estrategias adoptadas por la PKBI y Kebaya. Si comparamos estos dos paradigmas al detalle, se reconoce que ambos tratan la enfermedad desde una perceptiva centrada en el individuo y consideran que la implementación de los programas son "cuestiones técnicas" que pueden racionalizarse y cuantificarse de manera universal por medio del uso de tecnologías biomédicas y el análisis de comportamientos de riesgo e indicadores estadísticos (ONU, 2014: 34-37; ONUSIDA, 2004: 39-66). Esta construcción particular del VIH obvia el impacto que factores colectivos, socioculturales o estructurales - como el estigma y la discriminación - tienen en la prevención, transmisión y tratamiento de la enfermedad (Castro y Farmer, 2005; Farmer, 1992; 1996; Nguyen, 2010; Singer, 1996).

Las waria son un grupo históricamente discriminado y excluido social, política, religiosa y económicamente en el país, debido a su identidad de género (Boellstorff, 2004; KIWA y Toomistu, 2011;
Koeswinarno, 2007; Kortschak, 2010). En la actualidad, las waria no pueden entrar a determinados barrios de Jogjakarta en los que movimientos religiosos moderados, como el Nahdlatul Ulama (NU), y radicales, como el Front Pembela Islam - Frente de Defensores Islámicos—, ${ }^{13}$ las siguen considerando seres pecaminosos e inmorales ante los ojos de Dios (Boellstorff, 2014; Koeswinarno, s. f.; Safitri, 2013). La mayoría de las waria de la ciudad de Jogjakarta pertenecen al estrato social más marginal; subsisten en un contexto de vulnerabilidad constante en el que, por lo general, sólo son aceptadas y respetadas en ciertos nichos laborales, como trabajadoras sexuales, artistas de ludruk — danzas tradicionales-, artistas callejeras y estilistas (Balgos, Gaillard y Sanz, 2012; Koeswinarno, 2007; Taha, 2012). Esto da lugar a que muchas waria tengan dificultad para obtener ingresos regulares y combinen trabajos diurnos y nocturnos para subsistir (Hardon e Ilmi, 2014). Por ejemplo, una waria artista callejera que trabaja todos los días de la semana, de 9 de la mañana a 5 de la tarde, puede ganar alrededor de 200000 rupias indonesias (IDR) al mes — aproximadamente 300 pesos mexicanos (MXN) - ${ }^{14}$ Una waria trabajadora sexual puede cobrar entre 10000 y 50000 IDR por cliente - 16 y $80 \mathrm{MXN}$, respectivamente-. En Jogjakarta, el ingreso promedio mensual per cápita en 2010 fue de 249629 IDR - 400 MXN- (BPS, 2010). De acuerdo con la PKBI, alrededor de $60 \%$ de las waria de la ciudad son trabajadoras sexuales.

13 Nu es un grupo independiente de tradición suní, creado en 1926. Además de ser un partido político, funciona como organización caritativa que trabaja para combatir las deficiencias sociales del gobierno central. Front Pembela Islam es una organización radical religiosa indonesia, fundada en 1998. Es conocida por incitar al odio, la violencia y la discriminación en nombre del Islam. Ha sido acusada de perpetrar asesinatos y atentados en el país.

14 Tipo de cambio de enero de 2017. El resto de las conversiones monetarias en este artículo corresponde a la misma fecha. 
A pesar de que algunas waria destacan que el trabajo sexual tiene implicaciones positivas, como explorar y disfrutar de la sexualidad y la oportunidad de conseguir novios, muchas de ellas acaban decantándose por este modo de vida porque consideran que su condición social y educativa, y su identidad de género son una barrera para acceder a otros puestos laborales. Además, la gran competencia, inseguridad y precariedad del trabajo sexual y la necesidad imperiosa de obtener ingresos esconden situaciones de subordinación ante los clientes cuando éstos demandan no usar condón (Brummelhuis y Herdt, 1995: 115-134).

Otro elemento que influye en la implementación de los programas de prevención y tratamiento del VIH en Indonesia es la existencia de un fuerte estigma hacia los sujetos seropositivos (Hammar, 2010). En el caso de las waria, el estigma se basa en factores de carácter sociohistórico y religioso que han generalizado la percepción de que las waria son portadoras asintomáticas del VIH. Esta asociación directa se fundamenta en el conocimiento limitado que la población en general tiene respecto a la enfermedad y su transmisión (Bappenas, 2012: 6971; Indonesian National AIDS Commission, 2012: 34-35) y al constructo social prevalente de que ser waria es una condición pecaminosa no aceptada por Dios (Koeswinarno, s. f.; Safitri, 2013). La combinación de estos dos factores ha suscitado la creencia de que el Sida es una maldición divina que Dios ha enviado a las waria para castigarlas por su "condición anormal" y "conductas sexuales corrompidas". Las consecuencias de la propagación de esta percepción falaz ha sido un reforzamiento de la discriminación directa contra las waria seropositivas, que se materializa en rechazo social, violencia pública y exclusión de los barrios. Esta violencia estructural generada por el estigma puede actuar como un factor sindémico negativo y perpetuar la vulnerabilidad de las waria ante las ITS (Singer, 1996; Singer et al., 2006). Por lo general, las waria seropositivas son forzadas a abandonar a sus familias o zonas de residencia y sus pertenencias son quemadas. Las waria seropositivas no suelen confesar su condición a familiares o vecinos, sólo a waria en quienes confían y que las apoyan. Esto da lugar a que las waria seropositivas desarrollen mecanismos para evitar "situaciones sospechosas" que revelen su condición:

Mi sobrino llegó cuando me estaba tomando la pastilla y me dijo: "¿Qué medicina estás tomando?". "Es por el cansancio y la fatiga, eso es todo". Sin embargo, me preguntó de nuevo: “¿Por qué tantas?". "Porque así me lo ha dicho el doctor para que cure mi cansancio" (Mkala, 6 de abril de 2014).

Este fuerte estigma también implica que algunas waria expresen ansiedad y aprensión por el APV. Declaran que no quieren "arriesgarse" a saber si son seropositivas para no tener que "vivir en una mentira" o enfrentarse al rechazo social. Estas aprensiones a "ser descubiertas" por vecinos o familiares provocan inseguridad y desconfianza, que también influyen en la adscripción a la TAR. Algunas waria seropositivas en tratamiento deciden abandonarlo debido al compromiso de tener que esconder su condición: "para mí es sólo una cuestión de tiempo. Si muero hoy, será porque estoy hambrienta... pero si muero mañana, será por Sida. Para mí es lo mismo. La cuestión es que voy a morir" (Tiara, 11 de marzo de 2014).

A pesar de que el estigma social es una cuestión de peso para las waria, no representa una prioridad para la PKBI y Kebaya. Las organizaciones sólo trabajan con la población general en situaciones concretas, cuando el estigma produce tensiones en los barrios en los que conviven waria. En 2004, una de las letrinas comunitarias del barrio de Badram apareció con una señal que prohibía a las waria utilizarla, supuestamente para prevenir la transmisión del VIH. La PKBI y el grupo waria establecido en ese barrio se movilizaron para informar y educar a los 
vecinos sobre la enfermedad y la señal fue retirada en 2005. Sin embargo, el hecho de que las organizaciones no atiendan el problema del estigma de forma transversal en sus programas implica que se generen tensiones en los barrios en los que conviven waria:

Cuando el autobús llega, las personas de la comunidad no saben por qué viene y únicamente las waria van a ese autobús. La gente empieza a pensar: ¿qué hacen las waria allí? ¿Tienen alguna nueva epidemia o algo? Es sólo para las waria. Le dije todo esto a [un miembro de la PKBI]: éste es tu programa, no el mío. Mi programa es con la gente de aquí. Si quieres hacer algo con las waria, puedes llamarme para que las lleve a la PKBI, pero no vengas aquí, porque la gente no sabe acerca del Sida. Estoy asustada de que la gente pueda pensar: "eh, mira a las waria... ¡Están todas infectadas!" (Malula, 24 de abril de 2014).

Estas desavenencias entre los grupos de waria y las organizaciones también influyen en la adscripción de éstas a los programas de prevención y tratamiento del VIH. Algunas waria expresan impresiones de desconfianza hacia las organizaciones respecto a cómo la PKBI y Kebaya gestionan sus recursos y financiamiento. Afirman que ambas organizaciones "usan sus nombres" para obtener fondos, pero que después les imponen los programas sin considerar sus prioridades, opiniones o necesidades:

Es como Kebaya. El concepto era bueno al principio, pero con el tiempo cambiaron. Hay algunas cosas que son sorprendentes. Kebaya se centra en ODHA [Orang Dengan HIV, personas que tienen $\mathrm{VIH}$, pero hay algunas waria que aunque no sean ODHA aparecen en sus listas. Estas waria protestaron porque estaban usando sus nombres sin su consentimiento. Más personas, más miembros, más dinero (Lala, 4 de abril de 2014).
Las interpretaciones y creencias sobre la legitimidad y buenas prácticas de las organizaciones han dado lugar a la propagación de rumores y acusaciones que construyen visiones y realidades diferentes sobre las organizaciones:

Kebaya ya no tienen financiamiento [...] por lo que no pueden hacer un buen trabajo. Su trabajo no es bueno. En muchos casos dejaron morir a las waria que cuidaban. Estaban muy cansadas para cuidar de ellas, por lo que pensaban que era mejor dejar morir a la gente. El caso es que si hoy alguna amiga necesita sus medicinas, Kebaya se las da al día siguiente... y ya sabes qué pasa cuando es demasiado tarde. Mis amigas han muerto... una, dos, tres... 13 waria murieron en 2011. Estaba muy triste, lloré demasiado. ¿Y qué hizo Kebaya? Ellos tenían dinero para cuidar a todo el mundo... es muy triste. Y ahora no tienen dinero, después de que [organizaciones y fundaciones] vieron cómo trabajaba Kebaya (Aliza, 6 de marzo de 2014).

Los miembros de Kebaya reconocen que cometieron errores durante sus primeros años de operación debido a su falta de experiencia y limitaciones burocráticas. Antes de 2008, Kebaya sólo podía asistir a waria seropositivas que habían sido hospitalizadas. En esa época, muchas waria en Jogjakarta no tenían tarjetas de identidad debido al ostracismo familiar (Boellstorff, 2004), por lo que no podían solicitar el Jamkesmas — seguro de salud público para la gente con recursos limitados-y sus escasos recursos no les permitían costear su hospitalización. Hoy en día, Kebaya tiene autoridad legal para proveer TAR de manera gratuita a todas las waria, sin importar si tienen acceso al Jamkesmas. Por otro lado, las causas que llevaron a Kebaya a perder el apoyo financiero tuvieron lugar en 2010, cuando cambiaron los requerimientos de financiamiento de organizaciones en Jogjakarta. The Global Fund empezó a trabajar por medio de NU, que tenía una política restrictiva 
respecto a las organizaciones de la región que podían recibir fondos. Para NU sólo una organización que promoviera programas de prevención y tratamiento del VIH podía recibir financiamiento externo. Kebaya no fue seleccionada debido a su estatus de organización de reciente creación y los fondos recayeron en otra organización, llamada Victory Plus.

Al contrastar estas imputaciones, la perspectiva cambia. Sin embargo, la falta de canales de comunicación y medicación imparcial entre las organizaciones y las waria implica que algunas rechacen categóricamente cualquier tipo de intervención de la PKBI o Kebaya.

\section{Discusión: repensar los modelos hegemónicos del VIH}

Como se ha observado en el análisis previo, hay dimensiones estructurales, sociales e interpersonales que influyen en la adscripción de las waria a los programas de VIH. Al recalcar brevemente algunas de las contribuciones de la antropología al estudio de la construcción social del VIH, podemos entender de manera crítica las limitaciones de los paradigmas hegemónicos descritos. Uno de los aspectos más problemáticos que emergen en esta investigación es la definición de riesgo que se utiliza para diseñar las intervenciones. Como explica Iain Wilkinson, desde el siglo XIX la noción de riesgo se ha utilizado como una herramienta política y estadística (2010: 21). Por medio de una supuesta objetividad científica, la noción de riesgo ha sido empleada para racionalizar el mundo social y disciplinar poblaciones al atribuirles nociones de peligro, amenaza e inseguridad (Douglas, 1992). El problema de estas generalizaciones radica en que los sujetos incluidos en los llamados grupos de riesgo son despersonalizados e identificados indiscutiblemente como infectados, lo que promueve imágenes de sujetos estereotipados. La antropología ha buscado superar esta trampa epidemiológica por medio de dos contribuciones principales: i) redefinir la noción de riesgo como un concepto contextual, construido y dinámico, basado en las experiencias personales, las realidades socioculturales, la influencia de los medios de comunicación o las percepciones sociales prevalentes (Aronowirtz, 2009; Desmond, 2008; Kavanah y Broom, 1998; Nichter, 2003; Warner y Gabe, 2004), y ii) reemplazar el término "grupos en riesgo" por "poblaciones vulnerables" para enterrar la idea errónea de que todos los miembros del grupo determinado son "naturalmente propensos" a la transmisión. Esta distinción semántica ha servido para poner de manifiesto que la propia condición de sujeto no es una circunstancia sine qua non para identificar a aquellos individuos más proclives a la infección, sino que la vulnerabilidad está asociada a dimensiones socioculturales, condicionantes estructurales, la etnicidad o el género (Brummelhuis y Herdt, 1995; Gysels, Pool y Bwanika, 2001; Ra$\min , 2007:$ 129).

Otra crítica a los paradigmas hegemónicos que construyen el VIH ha sido su énfasis excesivo en el componente individual. Si bien los programas de prevención del VIH llevados a cabo durante años con las waria han servido para promover cambios de comportamiento, hemos podido examinar que el uso de condones no puede considerarse una elección individual y racional exclusivamente. Las dificultades que las waria afrontan para subsistir diariamente en un contexto de desigualdad estructural que no les permite acceder a trabajos regulares influyen directamente en su protección frente al VIH. La necesidad de asegurar ingresos en un contexto tan competitivo como el del trabajo sexual condiciona el hecho de que algunas waria cedan ante las exigencias y deseos de los clientes habituales o que incluso aparezcan sistemas de doble precio - con o sin condón-, como ocurre en contextos similares, como entre las trabajadoras sexuales africanas en España (Majuelos, 2014). 
Al mismo tiempo, la decisión de las waria de acceder al APV y la TAR no depende sólo de su discernimiento sobre los beneficios de estos servicios. El estigma social prevalente implica que el uso de estos recursos sea considerado una decisión trascendental que puede determinar el curso de sus vidas y las relaciones que mantienen con sus familiares y vecinos.

Por último, es importante centrarse en cómo el éxito de los programas está influido por las relaciones y percepciones de las organizaciones. Si bien el principal cometido de las ONG y organizaciones de base debería ser atender realidades sociosanitarias locales desde una perspectiva holística, al poseer un mayor conocimiento y contacto con dicha realidad (Appadurai, 2000), progresivamente se ha generalizado la implementación mundial de programas verticales y la reproducción sistemática de iniciativas diseñadas por instituciones internacionales, como ONUSIDA, con prácticas que encubren las demandas, necesidades y perspectivas de los grupos afectados (Keshavjee, 2015; Nguyen, 2010). Estas iniciativas tienden a interpretarse por las poblaciones asistidas como reproductoras de desigualdades, intereses economicistas, jerarquías sociales y políticas discriminatorias que prevalecen en sus sociedades, como algunas investigaciones en Filipinas, Nepal o India ponen de manifiesto (Aldaba et al., 2000; Ali, 2013; Lehman, 2007; Mosse, 2005).

En general, los programas de prevención y tratamiento del VIH propuestos por Kebaya y la PKBI no han llegado a instrumentarse de manera íntegramente positiva debido a la invisibilización sistemática de las complejas dimensiones estructurales, relacionales y colectivas que condicionan y atraviesan las decisiones individuales (Ramin, 2007: 130-131; Carey et al., 2004; Parker, Easton y Klein, 2000; Sommer y Parker, 2013; Sumartojo, 2000). Al centrarse en estas dimensiones estructurales, no sólo se pretende disminuir el impacto del VIH y prevenir su transmisión, sino además reducir las desigualdades sociales, económicas y políticas que subyacen a la perenne vulnerabilidad de las poblaciones afectadas. Las iniciativas de salud pública han ignorado estas propuestas debido a su "complejidad" y falta de definiciones e indicadores cuantificables (Gupta $e t$ al., 2008). Sin embargo, varios programas de prevención y tratamiento del viH han mostrado una efectividad reveladora cuando han tomado en consideración las dimensiones estructurales locales (Gupta et al., 2008). El recurrir a ejemplos de programas que han analizado el VIH desde una perspectiva estructural puede darnos claves de cómo complementar los esfuerzos que la PKBI y Kebaya han realizado hasta la fecha. Una posibilidad sería llevar a cabo programas de prevención comunitarios y en el hogar, sobre todo en los barrios de residencia de las waria, con la finalidad de propiciar ambientes de convivencia segura que reduzcan el estigma. Ha habido experiencias exitosas en países como Brasil o India (Aidala et al., 2005; Argento et al., 2011; Kerrigan et al., 2008). Otra estrategia complementaria positiva, también en India, es fomentar la prevención del VIH entre los clientes sexuales (Sahu et al., 2014) por medio de la erotización de los condones (Philpott, Knerr y Boydell, 2006). Por último, sería especialmente importante que ambas organizaciones promovieran programas educativos y de empoderamiento económico entre las waria - como hacía la PKBI antes de la epidemia del VIH- para favorecer su acceso a alternativas laborales y beneficiar su inclusión y aceptación en la sociedad.

Es necesario destacar la importancia de redefinir los paradigmas hegemónicos del VIH a favor de un enfoque inclusivo que construya la patología desde las perspectivas de profesionales de la salud, antropólogos médicos y las poblaciones afectadas, sobre todo. Los diálogos transversales, horizontales y multidisciplinarios que ponen de manifiesto las diversas y complementarias formas de entender y tratar la enfermedad y sus problemas son la única estrategia mediante la cual se pueden proponer soluciones realistas y equilibradas a la epidemia del VIH. 


\section{Conclusión}

Desde hace décadas, las organizaciones PKBI y Kebaya han implementado programas de prevención y tratamiento del VIH con las waria de Jogjakarta, debido al impacto que la patología ha tenido en este grupo minoritario. A pesar de que estos esfuerzos han logrado avances importantes, como la provisión gratuita de TAV o cambios de comportamiento sobre el uso del condón en el grupo, su desarrollo no ha resultado del todo satisfactorio ya que todavía hay waria que se niegan a realizarse las pruebas del VIH o a adscribirse a la terapia antirretroviral. De acuerdo con PKBI y Kebaya, estos problemas se deben a la falta de autocontrol, responsabilidad y educación entre las waria. Los resultados presentados en este artículo ilustran cómo factores estructurales, socioeconómicos e interpersonales no considerados por los programas, como la prevalencia de un fuerte estigma social contra las waria seropositivas, la negativa de los clientes a usar condones y la desconfianza hacia las organizaciones, inciden de manera directa en su efectividad. Con la finalidad de proponer estrategias que abarquen estas dimensiones, es necesario que los programas de prevención y tratamiento del VIH se diseñen por medio de enfoques transversales, horizontales, inclusivos y multidisciplinarios que articulen las distintas formas de entender y tratar el problema del VIH. En el caso de las waria, estas iniciativas incluirían llevar a cabo programas de prevención en la comunidad y en el hogar para generar ambientes de convivencia segura que reduzcan el estigma, fomentar la prevención del VIH entre los clientes sexuales y retomar programas educativos y de empoderamiento económico para favorecer el acceso a alternativas laborales alejadas del trabajo sexual, que además beneficien la inclusión y aceptación de las waria en la sociedad. D

\section{Bibliografía}

Aidala, Angela, Jay E. Cross, Ron Stall, David Harre y Esther Sumartojo, 2005, "Housing Status and HIV Risk Behaviours: Implications for Prevention and Policy", en AIDs and Behavior, vol. 9, núm. 3, pp. 251-65.

Aldaba, Fernando, Paula Antezana, Mariano Valderrama y Alan Fowler, 2000, "NGO Strategies Beyond Aid: Perspectives from Central and South America and the Philippines", en Third World Quarterly, vol. 21, núm. 4, pp. 669-683.

Ali, Ashraf H. M., 2013, "'Why Can't you Pay if you Can Eat?': Tales of how Women Encounter Unpleasant NGo Practices in Bangladesh", en Student Anthropologist, vol. 3, núm. 2, pp. 7-26.

Appadurai, Arjun, 2000, “Grassroots Globalization and the Research Imagination”, en Public Culture, vol. 12, núm. 1, pp. 1-19.

Argento, Elena et al., 2011, "Confronting Structural Violence in Sex Work: Lessons from a Community-Led HIV Prevention Project in Mysore, India”, en AlDs Care, vol. 23, núm. 1, pp. 69-74.

Aronowirtz, Robert A., 2009, "The Converged Experience of Risk and Disease”, en Milbank Quarterly, vol. 87, núm. 2, pp. $417-442$.

Badan Perencanaan Pembangunan Nasional (Bappenas), 2012, Laporan pencapaian tujuan pembangunan millennium di Indonesia 2011, Kementerian Perencanaan Pembangunan Nasional/Badan Perencanaan Pembangunan Nasional, Yakarta.

Badan Pusat Statistik (BPS), 2010, Daerah Istimewa Yogyakarta Dalam Angka, Badan Pusat Statistik-Subdivision of Regional Balance and Statistical Analysis, Jogjakarta.

Balgos, Benigno, J. C. Gaillard y Kristinne Sanz, 2012, "The Warias of Indonesia in Disaster Risk: The Case of the 2010 Mt Merapi Eruption in Indonesia”, en Gender \& Development, vol. 2, núm. 2, pp. 337-348.

Boellstorff, Tom, 2004, "Playing Back the Nation: Waria, Indonesian Transvestites”, en Cultural Anthropology, vol. 19, núm. 2, pp. 159-195.

— 2005, The Gay Archipelago: Sexuality and Nation in Indonesia, Princeton University Press, Princeton.

__ 2014, "Lessons from the Notion of 'Moral Terrorism'”, en Brigit Röttger-Rösssler y Thomas Stodulka (eds.), Feelings at the Margins. Dealing with Violence, Stigma and Isolation in Indonesia, University of Chicago Press/Campus, Nueva York, pp. 148-158.

Brummelhuis, Han ten y Gilbert Herdt, 1995, Culture and Sexual Risk. Anthropological perspectives on AIDS, Taylor and Francis, Londres. 
Carey, James W., Erin Picone-DeCaro, Mary Spink Neumann, Deborah Schwartz, Delia Easton y Daphne Cobb St. John, 2004, "HIV/AIDS Research and Prevention. Anthropological Contributions and Future Directions”, en Carol Ember y Melvin Ember (eds.), Encyclopaedia of Medical Anthropology. Health and IIIness in the World's Cultures, vol. I, Springer, Berlín, pp. 462-479.

Castro, Arachu y Paul Farmer, 2005, "El estigma del Sida y su evolución social: una visión desde Haiti", en Revista de Antropología Social, vol. 14, pp. 125-144.

Datta, Saugato y Sendhil Mullainathan, 2012, "Behavioral Design. A New Approach to Development Policy", CGD Policy Paper 016. Center for Global Development, Washington, D. C. Disponible en línea: <http://www.cgdev.org/files/1426679_file_Datta_Mullainathan_Behavioral_ Design.pdf>. Consultado el 10 de abril de 2015.

Desmond, Nicola, 2008, "Contrasting Risk Priorities for Health. The Social Construction of Risk Perception in Nw Tanzania”, ponencia presentada en el First International Sociological Association Forum of Sociology, 5 a 8 de septiembre, Barcelona.

Douglas, Mary, 1992, Risk and Blame. Essays in Cultural Theory, Routledge, Londres y Nueva York.

Farmer, Paul, 1992, AIDS and Accusation: Haiti and the Geography of Blame, University of California Press, Berkeley. , 1996, "On Suffering and Structural Violence: A View from Below”, en Daedalus, vol. 125, núm. 1, pp. 261-283.

Frey, Bruno S. y Ángel Serna, 1992, "El modelo económico del comportamiento humano: estado y perspectivas”, en Dereito: Revista Xurídica da Universidade de Santiago, vol. 1, núm. 1, pp. 197-211.

Gunawan, Suriadi, Soewarta Kosen y Chris Simms, 2006, "Indonesia”, en Eduard J. Beck y Lynn-Marie Holland (eds.), The HIV Pandemic: Local and Global Implication, Oxford University Press, Nueva York, pp. 317-332.

Gupta, Geeta Rao, Justin O. Parkhurst, Jessica A. Odgen, Peter Aggleton y Ajay Mahal, 2008, "Structural Approaches to HIV prevention”, en The Lancet, vol. 372, núm. 9640, pp. 764-775.

Gysels, M., R. Pool y K. Bwanika, 2001, "Truck Drivers, Middlemen and Commercial Sex Workers: AIDs and the Mediation of Sex in South West Uganda”, en AlDS Care, vol. 13, núm. 3, pp. 373-385.

Hadiwinata, Bob S., 2003, Politics of NGO in Indonesia: Developing Democracy and Managing a Movement, Routledge, Londres y Nueva York. Hammar, Lawrence J., 2010, Sin, Sex and Stigma: A Pacific Response to HIV and AIDS, Sean Kingston, Londres.

Hardon, Anita y Nurul IImi, 2014, "On Coba and Cocok: Youth-Led Drug-Experimentation in Eastern Indonesia", en Anthropology \& Medicine, vol. 21, núm. 2, pp. 217-29.

Indonesian National AIDS Commission, 2012, Republic of Indonesia Country Report on the Follow up to the Declaration of Commitment on HIV/ AIDS (UNGASS). Reporting period 2011-2012, Indonesian National AIDS Commission, Yakarta.

Jain, Anand, s. f., "Constructing an Epidemic: Epidemiology, Critical Medical Anthropology, and HIv". Disponible en línea: <http://www.virginia. edu/humanbiology/new_site_files/class_2004_papers_pdf/Anand\%205\%20page.pdf>. Consultado el 1 de mayo de 2015.

Joesoef, M. R., M. Gultom, I. D. Irana, J. S. Lewis, J. S. Moran, T. Muhaimin y C. A. Ryan, 2003, "High Rates of Sexually Transmitted Diseases among Male Transvestites in Jakarta, Indonesia”, en International Journal of STD \& AIDS, vol. 14, núm. 9, pp. 609-613.

Kavanagh, Anne M. y Dorothy H. Broom, 1998, “Embodied Risk: My Body, Myself?”, en Social Science and Medicine, vol. 46, núm. 3, pp. 437-444.

Kerrigan, Deanna, Paulo Telles, Helena Torres, Cheryl Overs y Christopher Castle, 2008, "Community Development and HIV/STI-Related Vulnerability among Female Sex Workers in Rio de Janeiro, Brazil”, en Health Education Research, vol. 23, núm. 1, pp. $137-145$.

Keshavjee, Salmaan, 2015, Blind Spot: How Neoliberalism Infiltrated Global Health. University of California Press, Oakland.

Koeswinarno, Oleh, s. f., "Islam and Marginalisation of Waria. An Effort to Reconstruct Islamic Law about Transgender", inédito.

__, 2007, Kehidupan Bergama Waria Muslim di Yogyakarta, Universitas Gadjah Mada, Jogjakarta.

Kortschak, Irfan, 2010, Invisible People: Poverty and Empowerment in Indonesia, The Lontar Foundation, Yakarta.

Lehman, Glen, 2007, "The Accountability of NGos in Civil Society and its Public Spheres", en Critical Perspectives on Accounting, vol. 18, núm. 6, pp. 645-669.

Majuelos, Francisco, 2014, "Trabajadoras sexuales africanas, entre el estigma y la crisis", en Gazeta de Antropología, vol. 30, núm. 2.

Menéndez, Eduardo, L., 1988, “Modelo médico hegemónico y atención primaria”, ponencia presentada en las Segundas Jornadas de Atención Primaria de la Salud, 30 de abril a 7 de mayo, Buenos Aires.

Morin, Jack, 2008, “'It's Mutual Attraction': Transvestites and Risk of HIV Transmission in Urban Papua”, en Leslie Butt y Richard Eves (eds.), Making Sense of AIDS: Culture, Sexuality, and Power in Melanesia, University of Hawai'i Press, Honolulu, pp. 41-59.

Mosse, David, 2005, Cultivating Development: An Ethnography of Aid Policy and Practice, Pluto Press, Londres.

Nguyen, Vinh-Kim, 2010, The Republic of Therapy: Triage and Sovereignity in West Africa's Time of AIDS, Duke University Press, Durham. 
Nicholas, Ford, Kemal Siregard, Rusli Ngatimin, 1997, "The Hidden Dimension: Sexuality and Responding of Threat of HIV/AIDS in South Sulawesi, Indonesia”, en Health \& Place, vol. 3, núm. 4, pp. 249-258.

Nichter, Mark, 2003, "Harm Reduction: A Core Concern for Medical Anthropology", en Barbara Herr Harthorn y Laury Oaks (eds.), Risk, Culture and Health Inequality: Shifting Perceptions of Danger and Blame, Praeger, Wesport, pp. 13-36.

Oetomo, Dédé, 2000, "Masculinity in Indonesia: Genders, Sexualities and Identities in a Changing Society", en Richard Parker, Regina Maria Barbosa y Peter Aggleton (eds.), Framing the Sexual Subject: The Politics of Gender, Sexuality, and Power, University of California Press, Berkeley, pp. 46-59.

—_, 2002, "Now you See it, Now you Don't: Homosexual Culture in Indonesia", en International Institute for Asian Studies Newsletter, núm. 29, p. 9.

O'Manique, Colleen, 2004, Neoliberalism and AIDS Crisis in Sub-Saharan Africa: Globalization's Pandemic, Palgrave Macmillan, Nueva York.

Organización de las Naciones Unidas (ONU), 2014, The Millenium Development Goals Report 2014, Organización de las Naciones Unidas, Nueva York.

Organización Mundial de la Salud (oms), 2014, Consolidated Guidelines on HIV Prevention, Diagnosis, Treatment and Care for Key Populations. Organización Mundial de la Salud, Ginebra. Disponible en línea: <http://apps.who.int/iris/bitstream/10665/128048/1/9789241507431_ eng.pdf?ua=1>. Consultado el 1 de febrero de 2015.

Parker, R. G., D. Easton y C. H. Klein, 2000, "Structural Barriers and Facilitators in HIV Prevention: A Review of International Research", en AIDS, núm. 14, supl. 1, pp. S22-S32.

Peletz, Michael P., 2006, "Transgenderism and Gender Pluralism in Southeast Asia since Early Modern Times", en Current Anthropology, vol. 47, núm. 2, pp. 309-340.

__, 2011, "Gender Pluralism: Muslim Southeast Asia since Early Modern Times”, en Social Research: An International Quarterly, vol. 78, núm. 2, pp. 659-686.

Pérez, Beatriz G., 2012, Antropología y desarrol/o: discurso, prácticas y actores, La Catarata, Madrid.

Philpott, Anne, Wendy Knerr y Vicky Boydell, 2006, "Pleasure and Prevention: When Good Sex Is Safer Sex”, en Reproductive Health Matters, vol. 14, núm. 28, pp. 23-31.

Pisani, E., P. Girault, M. Gultom, N. Sukartini, J. Kumalawati, S. Jazan y E. Donegan, 2004, "HIV, Syphilis Infection, and Sexual Practices among Transgenders, Male Sex Workers, and other Men who Have Sex with Men in Jakarta, Indonesia”, en Sexually Transmitted Infections, vol. 80, núm. 6, pp. 536-540.

Prabawanti, Ciptasari et al., 2011, "HIV, Sexually Transmitted Infections and Sexual Risk Behaviour Among Transgenders in Indonesia”, en AIDS and Behaviour, vol. 15, núm. 3, pp. 663-673.

Programa Conjunto de las Naciones Unidas sobre el VIH/Sida (ONUSIDA), 2004, 2004 Report on the Global AIDS Epidemic. 4th Global Report, Programa Conjunto de las Naciones Unidas sobre el viH/Sida, Ginebra.

_ _ 2013, "Epidemiological Fact Sheet on HIV and AIDS". Disponible en línea: <http://www.unaids.org/sites/default/files/epidocuments/ IDN.pdf>. Consultado el 16 de febrero de 2015.

Ramin, Brodie, 2007, “Anthropology Speaks to Medicine: The Case HIV/AIDs in Africa”, en McGill Journal of Medicine, vol. 10, núm. 2, pp. 127-132.

Safitri, Dian Maya, 2013, "The Politics of Piety in the Pondok Pesantren Khusus Waria Al-Fattah Senin Kamis Yogyakarta. Negotiating the Islamic Religious Embodiment”, en Jajat Burhanuddin y Kees van Dijk (eds.), Islam in Indonesia: Contrasting Images and Interpretations, Amsterdam University Press, Ámsterdam.

Sahu, Damodar, Arvind Pandey, Ram Manohar Mishra, Niranjan Saggurti, Shekhar Setu e Indra Raj Singh, 2014, "An Appraisal of Sexual Behaviors, STI/HIV Prevalence, and HIV Prevention Programs among Truckers in India: A Critical Literature Review", en World Journal of AIDS, núm. 4, pp. 206-218.

Singer, Merrill, 1996, "A Dose of Drugs, a Touch of Violence, A Case of AIDS: Conceptualizing the sAVA Syndemic", en Free Inquiry in Creative Sociology, vol. 24, núm. 2, pp. 99-110.

Singer, Merrill y Scott Clair, 2003, "Syndemics and Public Health: Reconceptualizing Disease in Bio-Social Context", en Medical Anthropology Quarterly, vol. 17, núm. 4, pp. 423-441.

Singer, Merrill, Pamela I. Erickson, Louise Badiane, Rosemary Diaz, Dugeidy Ortiz, Traci Abraham y Anna Marie Nicolaysen, 2006, "Syndemics, Sex and the City: Understanding Sexually Transmitted Diseases in Social and Cultural Context”, en Social Science and Medicine, vol. 63, núm. 8, pp. 2010-2021.

Sommer, Marni y Richard Parker (eds.), 2013, Structural Approaches in Public Health, Routledge, Londres. 
Sumartojo, Esther, 2000, "Structural Factors in HIV Prevention: Concepts, Examples and Implications for Research", en AIDS, núm. 14, supl. 1, pp. S3-S10.

Taha, Nur'Ain, 2012, Let me Be a Servant of God: A Study of Pondok Pesantren Khusus Waria Senin-Kamis in Yogyakarta, tesis de máster, Department of Southeast Asian Studies/National University of Singapore, Singapur.

Thomsen, Sarah, M. Stalker y C. Toroitich-Ruto, 2004, “Fifty Was to Leave your Rubber: How Men in Mombasa Rationalise Unsafe Sex”, en Sexually Transmitted Infections Journal, núm. 80, pp. 430-434.

Valentine, David, 2007, Imagining Transgender: An Ethnography of a Category, Duke University Press, Durham.

Warner, Joanne y Jonathan Gabe, 2004, "Risk and Liminality in Mental Health Social Work", en Health, Risk and Society, vol. 6, núm. 4, pp. 387-399.

Wilkinson, lain, 2010, Risk, Vulnerability and Everyday Life, Routledge, Londres.

\section{Filmografía}

KIWA y Terje Toomistu (dirs.), 2011, Wariazone, KIWA \& CECE, Indonesia.

\section{Entrevistas}

Aliza, Jogjakarta, Indonesia, 6 de marzo de 2014.

Kira, Jogjakarta, Indonesia, 6 de abril de 2014.

Lala, Jogjakarta, Indonesia, 4 de abril de 2014.

Malula, Jogjakarta, Indonesia, 24 de abril de 2014.

Mkala, Jogjakarta, Indonesia, 6 de abril de 2014.

Nancy, Jogjakarta, Indonesia, 12 de marzo de 2014

Tiara, Jogjakarta, Indonesia, 11 de marzo de 2014. 